OLIVEIRA, A.P.; ALVES, E.U.; ALVES, A.U.; DORNELAS, C.S.M.; SILVA, J.A.; PÔRTO, M.L.; ALVES, A.V. Produção de feijão-fava em função do uso de doses de fósforo em um Neossolo Regolítico. Horticultura Brasileira, Brasília, v. 22, n. 3, p. 543-546, jul-set 2004.

\title{
Produção de feijão-fava em função do uso de doses de fósforo
}

\author{
Ademar P. de Oliveira ${ }^{1}$; Edna U. Alves²; Adriana U. Alves ${ }^{3,4}$; Carina S.M. Dornelas ${ }^{3,4}$; Jandiê A. da Silva ${ }^{3}$; \\ Mônica L. Pôrto ${ }^{3}$; Amarlete V. ALves ${ }^{1}$ \\ ${ }^{1}$ UFPB, CCA, C. Postal 02, 58397-000 Areia-PB, Bolsista CNPq, E-mail: ademar @ cca.ufpb.br; ${ }^{2}$ UNESP, 14870-000 Jaboticabal-SP; \\ ${ }^{3}$ Graduação em Agronomia, UFPB; ${ }^{4}$ Bolsistas PIBIC/CNPq
}

\section{RESUMO}

O fósforo é um importante nutriente para as plantas e sua presença no solo promove o crescimento e eleva a produção das hortaliças. O presente trabalho, realizado na Universidade Federal da Paraíba, em Areia, em um NEOSSOLO REGOLÍTICO Psamítico típico no período de dezembro/2001 a julho/2002, teve por objetivo avaliar a resposta do feijão-fava, cultivar "Orelha de Vó", a diferentes doses de $\mathrm{P}_{2} \mathrm{O}_{5}$. $\mathrm{O}$ delineamento experimental utilizado foi em blocos casualizados com cinco tratamentos $(0 ; 100 ; 200 ; 300 ; 400 \mathrm{e}$ $500 \mathrm{~kg} \mathrm{ha}^{-1} \mathrm{de} \mathrm{P}_{2} \mathrm{O}_{5}$ ) e com quatro repetições. Cada parcela continha 40 plantas espaçadas em $1,0 \mathrm{~m} \times 0,50 \mathrm{~m}$. As produções máximas estimadas de grãos verdes e secos $\left(5,2 \mathrm{e} 2,7 \mathrm{t} \mathrm{ha}^{-1}\right)$, respectivamente, ocorreram com 309 e $302 \mathrm{~kg} \mathrm{ha}^{-1}$ de $\mathrm{P}_{2} \mathrm{O}_{5}$. As doses de $\mathrm{P}_{2} \mathrm{O}_{5}$ que proporcionaram maiores retornos econômicos foram $291 \mathrm{~kg} \mathrm{ha}^{-1}$ para a produção de grãos verdes e $281 \mathrm{~kg} \mathrm{ha}^{-1}$ para produção de grãos secos, sendo as receitas previstas para a aplicação destas, correspondentes às produtividades de $4,1 \mathrm{e} 1,8 \mathrm{t} \mathrm{ha}^{-1}$, respectivamente. As doses mais econômicas compreenderam mais de $80 \%$ daquelas responsáveis pelas produções máximas, constituindo um indicativo da viabilidade econômica do emprego de fósforo no cultivo de feijãofava. As doses de $\mathrm{P}_{2} \mathrm{O}_{5}$ com as quais obtiveram-se as máximas produções e retornos econômicos quanto a produção de grãos verdes e secos, se correlacionam, respectivamente, com 57,1 e 56,3 e com 55,0 e $53,8 \mathrm{mg} \mathrm{dm}^{-3}$ de P disponível pelo extrator de Melich 1. Probabilidades minimizadas de ocorrência de resposta dessa cultura à adubação fosfatada em solos semelhantes ao do presente estudo, para a produção de grãos verdes e secos, serão obtidas quando os teores de $\mathrm{P}$ disponível forem superiores a 55,0 e $53,8 \mathrm{mg} \mathrm{dm}^{-3}$. A concentração média de $P$ nas folhas do feijão-fava, aos 120 dias após a semeadura, em função das doses de $\mathrm{P}_{2} \mathrm{O}_{5}$ foi de $3,4 \mathrm{~g} \mathrm{~kg}^{-1}$. As doses de 291 e $281 \mathrm{~kg} \mathrm{ha}^{1}$ de $\mathrm{P}_{2} \mathrm{O}_{5}$, respectivamente, devem ser as recomendadas para aplicação no solo em estudo, visando a produção de grãos verdes e secos de feijão-fava.

Palavras-chave: Phaseolus lunatus L, adubação, grãos verdes, grãos secos, produção.

\section{ABSTRACT. \\ Lima bean production as a result of the application of phosphorus levels}

Phosphorus is an important mineral nutrient for vegetables. This work was conducted at Universidade Federal da Paraíba, in Areia, Brazil, from December/2001 to July/2002, aiming to evaluate the effect of levels of $\mathrm{P}_{2} \mathrm{O}_{5}$ on the yield of lima bean, cv. "Orelha de Vó". The experimental design was a randomized block with five treatments $\left(0 ; 100 ; 200 ; 300 ; 400\right.$ and $500 \mathrm{~kg} \mathrm{ha}^{-1}$ of $\left.\mathrm{P}_{2} \mathrm{O}_{5}\right)$, and four replications. Each plot consisted of 40 plants spaced $1.0 \mathrm{~m}$ between rows and $0.50 \mathrm{~m}$ between plants in each row. The estimated maximum yield of green and dry beans (5.2 and $2.7 \mathrm{t} \mathrm{ha}^{-1}$, respectively) corresponded, to the dosages of 309 and $302 \mathrm{~kg} \mathrm{ha}^{-1}$ of $\mathrm{P}_{2} \mathrm{O}_{5}$. The levels $291 \mathrm{~kg} \mathrm{ha}^{-1}$ and $281 \mathrm{~kg} \mathrm{ha}^{-1}$ of $\mathrm{P}_{2} \mathrm{O}_{5}$ provided, respectively, the greater economic return for the yield of green $\left(4.1 \mathrm{t} \mathrm{ha}^{-1}\right)$ and dry $\left(1.8 \mathrm{t} \mathrm{ha}^{-1}\right)$ beans. The most economic levels included more than $80 \%$ of those dosages responsible for the maximum yields and indicated the economic viability of phosphorus utilization on lima bean crop. The $\mathrm{P}_{2} \mathrm{O}_{5}$ levels which promoted the maximum yield and the maximum economic return for green and dry beans yield were respectively, with $57.1 ; 56.3 ; 55.0$ and $53.8 \mathrm{mg} \mathrm{dm}^{-3}$ of available $\mathrm{P}$ for the extractor of Melich 1. The lima bean response to the phosphorus fertilization in soils with similar fertility used in the present study, for green and dry beans yield, will be reduced at levels of available $\mathrm{P}$ superior to 55.0 and $53.8 \mathrm{mg} \mathrm{dm}^{-3}$. The average concentration of $\mathrm{P}$ in the leaves of lima bean, 120 days after sowing, in function of levels of $\mathrm{P}_{2} \mathrm{O}_{5}$ was of $3.4 \mathrm{~g} \mathrm{~kg}^{-1}$. For the soil of this study the application of 291 and $281 \mathrm{~kg} \mathrm{ha}^{-1}$ of $\mathrm{P}_{2} \mathrm{O}_{5}$ is more recommended to establish the lima bean respectively, for green and dry beans yield.

Keywords: Phaseolus lunatus L, fertilization, green grains, dry grains, yield.

\section{(Recebido para publicação em 23 de outubro de 2002 e aceito em 30 de abril de 2004)}

$\mathrm{O}$ feijão-fava (Phaseolus lunatus L) também conhecido por feijão-delima, fava-de-lima, simplesmente fava, é uma das alternativas de renda e alimento para a população da região Nordeste do Brasil, que o consome sob a forma de grãos maduros ou verdes. É produzido por pequenos produtores que utilizam principalmente cultivares de crescimento indeterminado. O estado da Paraíba, onde o feijão fava é cultivado em quase todas as micro-regiões, desta- ca-se como um dos maiores produtores nacionais. Em algumas regiões tem se constatado níveis baixos de produtividade, devido principalmente à falta de um programa de pesquisas sobre nutrição mineral.

A grande maioria dos solos brasileiros é ácida de baixa fertilidade e elevada capacidade de retenção de fósforo o que leva à necessidade de aplicação de elevadas doses de fosfatos, contribuindo para o aumento nos custos de produ- ção, e reduzir os recursos naturais não renováveis que originam esses insumos (Moura et al., 2001). Para se obter alta produtividade é necessário uma adubação fosfatada (Fageria, 1990), o que tem ocasionado a intensificação da busca de doses mais adequadas para as culturas e que possibilitem maiores retornos econômicos.

As quantidades de fósforo retiradas do solo pelas hortaliças são geralmente baixas, principalmente quando compa- 
radas com o nitrogênio e o potássio. Entretanto, apesar dessa aparente baixa exigência, os teores desse nutriente na solução do solo, bem como a velocidade do seu restabelecimento na mesma, não são suficientes para atender às necessidades das culturas. Como conseqüência, nas adubações é o fósforo que entra em maiores proporções (Coutinho et al., 1993). Seu fornecimento em dose adequada favorece o desenvolvimento do sistema radicular aumentando a absorção de água e de nutrientes; aumenta o vigor das plantas oriundas de semeadura direta; favorece a floração e a frutificação e aumenta a qualidade e o rendimento dos produtos colhidos (Filgueira, 2000).

Em solos naturalmente bem supridos com fósforo, a sua adição não afeta a produção nem a qualidade das hortaliças (Fontes et al., 1997). Entretanto, para diferentes classes de teores desse nutriente no solo são obtidas curvas de respostas correspondentes (Raij, 1991). Os solos, porém, diferem quanto à imobilização de fosfatos, e as condições que favorecem os maiores índices do fenômeno são maiores teores de argila, maior ocorrência na argila de óxidos de ferro e alumínio e menores valores de $\mathrm{pH}$ (Raij, 1983). Em condições de solos com pequena CMAP (capacidade máxima de adsorção de P), como os arenosos, é preciso maior valor I (fator intensidade), ou seja, a concentração ótima para atender a demanda da planta; bem como para uma mesma quantidade de fósforo colocada no solo, devem ser encontrados valores I bem maiores nos solos arenosos (Novais e Smyth, 1999).

Muitos trabalhos brasileiros mostram respostas marcantes do fósforo na elevação do rendimento das hortaliças, em função da sua aplicação (Seno et al., 1994; Fontes et al., 1997; Vieira et al., 1998; Silva, et al., 2001b). Para o feijoeiro comum, este nutriente também tem proporcionado as maiores e mais freqüentes respostas e sua baixa disponibilidade no solo afeta negativamente o crescimento das plantas e sua produção (Pastorini et al., 2000). Contudo, embora o fósforo seja o nutriente que as hortaliças mais respondem (Filgueira, 2000), pouco se conhece, ainda, a respeito das quantidades a utilizar, que per- mitam a obtenção de rendimentos satisfatórios no feijão-fava. As poucas informações a respeito da sua nutrição, relatam que, embora retire muito potássio do solo (Vieira, 1992), nas regiões Sul e Sudeste, em solos com baixa fertilidade, deve-se aplicar fósforo no plantio, juntamente com matéria orgânica (Filgueira, 2000).

Não existem trabalhos visando recomendações de fósforo para a cultura do feijão-fava nas condições do estado da Paraíba, razão pela qual as sugestões de aplicação desse nutriente nessa hortaliça são formuladas adequando-se informações de outras regiões produtoras. Nesse sentido, o objetivo do presente trabalho foi verificar o comportamento do feijão-fava quando submetido a doses de $\mathrm{P}_{2} \mathrm{O}_{5}$.

\section{MATERIAL E MÉTODOS}

O trabalho foi conduzido no campo experimental da Universidade Federal da Paraíba, em Areia, em NEOSSOLO REGOLÍTICO Psamítico típico textura franca (Embrapa, 1999), de dezembro/ 2001 a julho/2002, respectivamente, datas da semeadura à última colheita. A análise química do solo da área experimental resultou: $\mathrm{pH}_{2} \mathrm{O}=6,3 ; \mathrm{P}$ disponível $\left(\right.$ extrator Mehlich 1) $=11,1 \mathrm{mg} \mathrm{dm}^{-3} ; \mathrm{K}$ disponível $=9,0 \mathrm{mg} \mathrm{dm}^{-3} ; \mathrm{Na}^{+}=0,03 \mathrm{cmol}$ $\mathrm{dm}^{-3}, \mathrm{H}^{+}+\mathrm{Al}^{+3}=1,07, \mathrm{Al}^{+3}=0,00 \mathrm{cmol}^{\mathrm{c}}$ $\mathrm{dm}^{-3} ; \mathrm{Ca}^{+2}=2,4 \mathrm{cmol}_{\mathrm{c}} \mathrm{dm}^{-3} ; \mathrm{Mg}^{+2}=0,2$ $\mathrm{cmol} \mathrm{dm}^{-3} ; \mathrm{SB}=2,65 \mathrm{cmol} \mathrm{dm}^{-3} ; \mathrm{CTC}=$ $3,72 \mathrm{cmol}_{\mathrm{c}} \mathrm{dm}^{-3}$ e matéria orgânica $=16,1$ $\mathrm{g} \mathrm{dm}^{-3}$. O esterco bovino utilizado apresentou as seguintes características em base seca: $\mathrm{P}=3,6 \mathrm{~g} \mathrm{~kg}^{-1} ; \mathrm{K}=4,1 \mathrm{~g} \mathrm{~kg}^{-1} ; \mathrm{N}=3,8$ $\mathrm{g} \mathrm{kg}^{-1}$; matéria orgânica $=182 \mathrm{~g} \mathrm{dm}^{-3} \mathrm{e}$ relação $\mathrm{C} / \mathrm{N}=10 / 1$. A área experimental apresenta topografia plana e os teores de areia, silte e argila foram, respectivamente, 841,88 e $70 \mathrm{~g} \mathrm{~kg}^{-1}$, conforme metodologia definida por Day (1965).

As plantas foram dispostas em fileiras, tutoradas pelo método de varas cruzadas, no espaçamento de $1,0 \mathrm{~m}$ x 0,5 $\mathrm{m}$, em parcelas com 40 plantas, sendo 20 empregadas para avaliar grãos verdes e 20 pra avaliar grãos secos. Os tratamentos consistiram de seis doses de $\mathrm{P}_{2} \mathrm{O}_{5}\left(0 ; 100 ; 200 ; 300 ; 400\right.$ e $\left.500 \mathrm{~kg} \mathrm{ha}^{-1}\right)$, disposto em blocos casualizados com quatro repetições.
A adubação de plantio constou da aplicação de forma localizada de $20 \mathrm{t}$ $\mathrm{ha}^{-1}$ de esterco bovino curtido e seco, das doses de $\mathrm{P}_{2} \mathrm{O}_{5}$ mencionadas acima, utilizando-se como fonte superfosfato simples, e de $170 \mathrm{~kg} \mathrm{ha}^{-1}$ de cloreto de potássio, sete dias antes da semeadura. Em cobertura, aplicou-se $400 \mathrm{~kg} \mathrm{ha}^{-1}$ de sulfato de amônio, em duas parcelas iguais, aos 30 e aos 60 dias após a semeadura. As doses de esterco bovino, de cloreto de potássio e de sulfato de amônio, foram definidas conforme recomendação do Laboratório de Química e de Fertilidade do Solo do Centro de Ciências Agrárias da UFPB, baseada nas características química do solo.

Durante a condução da cultura foram realizadas pulverizações à base de Deltametrina 2,5E a cada quinze dias, visando o controle da cigarrinha verde (Empoasca braemer) e da lagarta-dasvagens (Etiella zinckenella). No período de ausência de chuvas, foi realizada irrigação por aspersão. Efetuaram-se também capinas com auxílio de enxada, procurando-se manter a cultura livre de plantas invasoras. O plantio foi realizado pelo método de semeadura direta, colocando-se quatro sementes por cova da cultivar "Orelha de Vó". Aos 15 dias realizou-se o desbaste, deixando-se duas plantas por cova. As colheitas, em número de oito, foram realizadas à medida que a vagem iniciava sua maturação para obtenção do rendimento de grãos verdes e quando se apresentavam secas para obtenção de grãos secos. Ao final da colheita efetuou-se a amostragem do solo (0-20 cm de profundidade), coletando-se dez amostras simples ao acaso por parcela para se determinar as concentrações de $\mathrm{P}$ disponível pelo extrator Melich I.

Os resultados foram submetidos às análises de variância e de regressão, sendo selecionado para expressar o comportamento das doses de $\mathrm{P}_{2} \mathrm{O}_{5}$ o modelo significativo de maior ordem que tenha apresentado maior coeficiente de determinação, utilizando-se o "software" SAEG (2000).

Também foram determinadas as doses de $\mathrm{P}_{2} \mathrm{O}_{5}$ capazes de promoverem os maiores retornos econômicos para a produção de grãos verdes e secos, conforme Raij (1991). Os valores utilizados 
para as variáveis grãos verdes e secos e $\mathrm{P}_{2} \mathrm{O}_{5}$ vigentes em Areia (PB) em agosto de 2002 foram: $\mathrm{R} \$ 2,00 / \mathrm{kg}$ de grãos verdes, $\mathrm{R} \$ 2,50 / \mathrm{kg}$ de grãos secos e $\mathrm{R} \$$ $3,50 / \mathrm{kg}$ de $\mathrm{P}_{2} \mathrm{O}_{5}$, ressaltando porém, que essas relações de preços podem variar a cada ano, conforme a demanda e oferta. No entanto, a fim de atenuar os problemas de variação cambial, trabalhou-se com uma relação de troca ao invés de moeda corrente (Natale et al., 1996), procurando-se assim dados mais estáveis. Portanto, a "moeda" utilizada nos cálculos, foi o próprio grão verde e seco, considerando-se as seguintes relações de equivalência: quilograma de $\mathrm{P}_{2} \mathrm{O}_{5} / \mathrm{kg}$ de grãos verdes e secos iguais, respectivamente, a 1,75 e 1,4 , sendo as doses mais econômicas calculadas baseadas na derivadas das equações de regressão entre as produções de grãos verdes e secos e as doses de $\mathrm{P}_{2} \mathrm{O}_{5}$ por meio da relação de $\mathrm{dy} / \mathrm{dx}=\mathrm{a}_{1}+2 \mathrm{a}_{2} \mathrm{x}$. As doses mais econômicas ( $\mathrm{x}$ ' ) foram então calculadas por:

$$
\begin{gathered}
x^{\prime}=a_{1}-\text { relação de equivalência } \\
2\left(-a_{2}\right)
\end{gathered}
$$

Onde $\mathbf{x}$ ' representa a dose econômica, $\mathbf{a}_{\mathbf{1}}$ a taxa de incremento de produção e $\mathbf{a}_{2}$, o ponto de máxima produção.

\section{RESULTADOS E DISCUSSÃO}

Os efeitos da adubação fosfatada sobre a produção de grãos verdes e secos de feijão-fava, ajustaram-se a modelos quadráticos (Figura 1). As produções máximas de grãos verdes e secos estimadas por derivações em, respectivamente, 5,2 e 2,7 tha-1, ocorreram com 309 e $302 \mathrm{~kg} \mathrm{ha}^{-1}$ de $\mathrm{P}_{2} \mathrm{O}_{5}$, respectivamente. Estes resultados, evidenciam uma boa produção do feijão-fava, cultivar "Orelha de Vó" na micro-região de Areia e supera os rendimentos obtidos por Vieira (1978) nas condições de Viçosa (MG) e por Lyman (1983) na Colômbia.

As doses de $\mathrm{P}_{2} \mathrm{O}_{5}$ capazes de proporcionar maior retorno econômico para as produções de grãos verdes e secos de feijão-fava, foram determinadas, respectivamente, pelas seguintes equações: $(30,069$ - 1,75$) /(2 \times 0,0486)$ e $(14,659$ $1,4) /(2 \times 0,0243)$. Dessa forma, as doses mais econômicas foram, respectivamente, de 291 e $281 \mathrm{~kg} \mathrm{ha}^{-1}$. As receitas

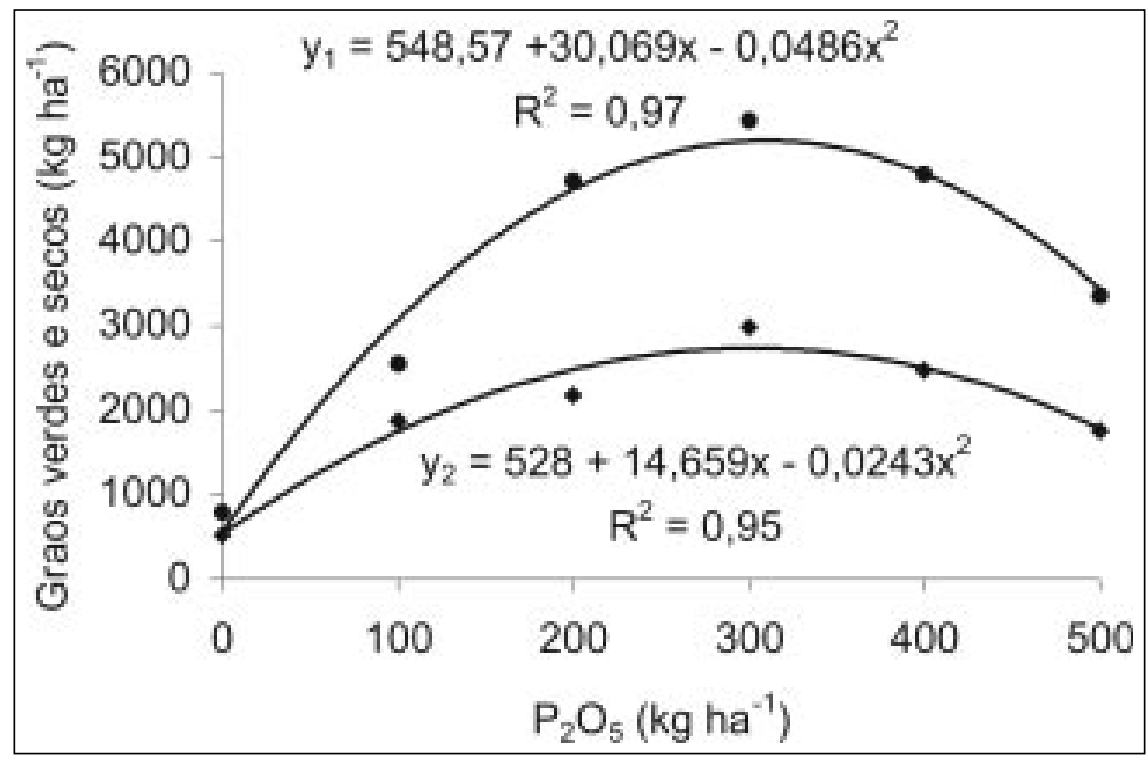

Figura 1. Produção de grãos verdes $\left(\mathrm{y}_{1}\right)$ e de grãos secos $\left(\mathrm{y}_{2}\right)$ de feijão-fava, cultivar "Orelha de Vó”, em função do uso de doses de $\mathrm{P}_{2} \mathrm{O}_{5}$ em NEOSSOLO REGOLÍTICO Psamítico típico textura franca. Areia, UFPB, 2002.

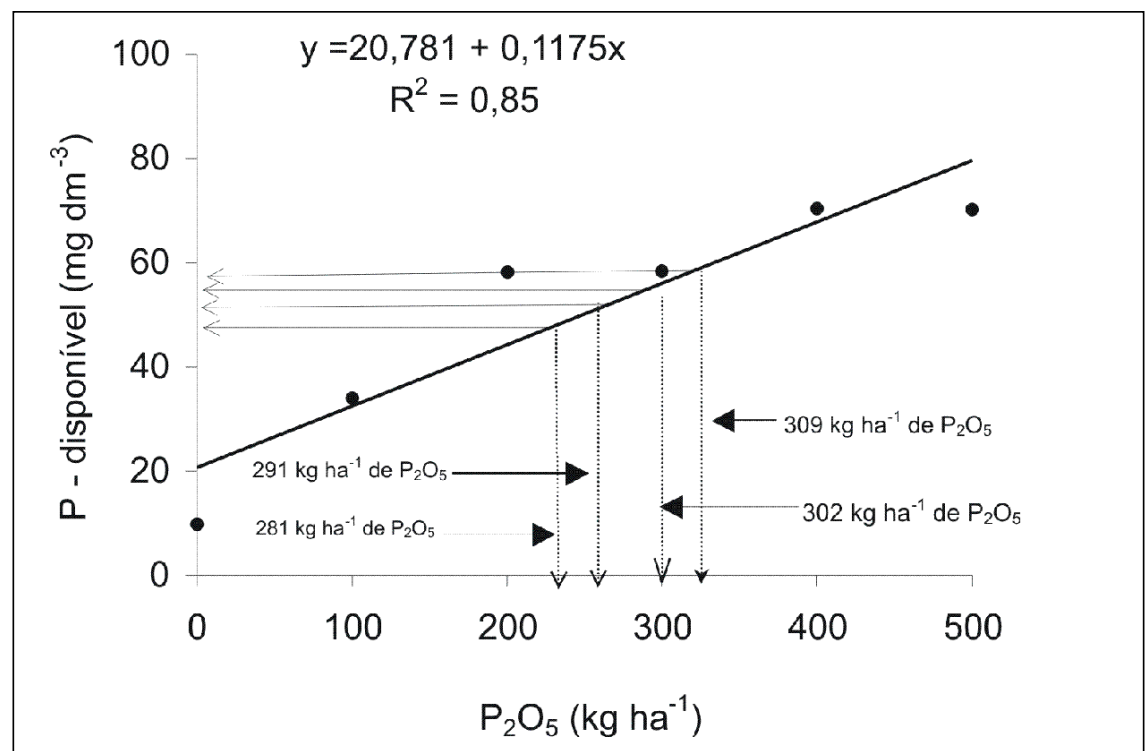

Figura 2. Teores de $\mathrm{P}$ disponível (Melich I), em função de doses de $\mathrm{P}_{2} \mathrm{O}_{5}$ para o estabelecimento de feijão-fava cultivar "Orelha de Vó" em NEOSSOLO REGOLÍTICO Psamítico típico textura franca. Areia, UFPB, 2002.

previstas devido à aplicação do $\mathrm{P}_{2} \mathrm{O}_{5}$ foram calculadas pelos aumentos de produções (4,6 e 2,2 t ha-1 de grãos verdes e secos), respectivamente, substituindo as doses mais econômicas, pelo " $\mathrm{x}$ " das derivadas segundas das equações de regressão, deduzido dos custos do $\mathrm{P}_{2} \mathrm{O}_{5}$ (509 kg ha-1 de grãos verdes e $393 \mathrm{~kg}$ $\mathrm{ha}^{-1}$ de grãos secos), resultando numa receita correspondente à produtividade de 4,1 e 1,8 t ha $^{-1}$ de grãos verdes e secos, respectivamente.
As doses mais econômicas representaram mais de $80 \%$ daquelas responsáveis pelas produções máximas o que pode indicar a viabilidade econômica do emprego de fósforo no cultivo de feijão-fava. Segundo Lobato (1982) a melhor eficiência econômica para o fósforo encontra-se entre 80 a $95 \%$ da produção máxima. Também, as doses de $\mathrm{P}_{2} \mathrm{O}_{5}$ responsáveis pelas máximas produções e pelos máximos retornos econômicos para a produção de grãos ver- 
des e secos, se correlacionaram, respectivamente, com 57,1 e 56,3 e com 55,0 e $53,8 \mathrm{mg} \mathrm{dm}^{-3}$ de $\mathrm{P}$ disponível residual, determinado pelo extrator Melich I (Figura 2).

De maneira geral, as doses de $\mathrm{P}_{2} \mathrm{O}_{5}$ apresentaram efeitos significativos tanto na produção do feijão-fava, quanto para os teores de P disponível. Dessa maneira, considerando-se que as produções de máximos retornos econômicos ficaram acima de $80 \%$ daquelas responsáveis pelas produções máximas, a probabilidade de ocorrência de resposta do feijãofava a adubação fosfatada, em solos semelhantes ao do presente estudo, será minimizada quando os teores de $\mathrm{P}$ disponível forem superiores a 55,0 para a produção de grãos verdes e a $53,8 \mathrm{mg}$ $\mathrm{dm}^{-3}$ para a produção de grãos secos.

O baixo teor inicial de fósforo no solo, conforme Novais e Smyth (1999), possivelmente tenha sido um forte aliado para a resposta do feijão-fava a esse elemento. Os efeitos das adubações fosfatadas sobre as culturas são especialmente acentuadas em solos de baixa fertilidade (Raij, 1991).

O fornecimento de doses adequadas de fósforo, desde o início do desenvolvimento, estimula o desenvolvimento radicular, é importante para a formação dos primórdios das partes reprodutivas, é essencial para a boa formação de frutos e, em geral, incrementa a produção nas culturas, (Raij, 1991). Portanto, é provável que durante o crescimento e desenvolvimento das plantas, as doses de $\mathrm{P}_{2} \mathrm{O}_{5}$ responsáveis pelas máximas produções juntamente com os nutrientes adicionados ao solo, supriram de forma equilibrada as necessidades nutricionais do feijão-fava. O equilíbrio entre elementos nutritivos é mais importante no ganho da produtividade do que maiores quantidades de macronutrientes isoladamente (Primavesi, 1985). Maiores produções de grãos de feijão comum em função do fornecimento de doses adequadas de fósforo, foram relatados por diversos autores (Andrade et al., 1998; Silva et al.,2001a).

Não foram observados sintomas de deficiência de fósforo, mesmo no tratamento testemunha. Esse fato pode indicar, que provavelmente o feijão-fava tenha relativa eficiência para a produção de biomassa, ou que as respostas aos tratamentos tenham resultados da dis- ponibilidade de outros nutrientes veiculados pelos fertilizantes, ou ainda que tenha se tornado disponível pelas mudanças no ambiente do solo, ocasionado pelo esterco bovino utilizado. Em solos argilosos, fato semelhante foi observado por Vieira (1995), com mandioquinha salsa.

Para o estabelecimento do feijãofava em Neossolo Regolítico Psamítico Típico, textura franca, com característica química semelhante ao utilizado nessa pesquisa, deve ser recomendado a aplicação de 291 ou de $281 \mathrm{~kg} \mathrm{ha}^{-1}$ de $\mathrm{P}_{2} \mathrm{O}_{5}$ quando o objetivo for respectivamente, produzir grãos verdes ou secos. No entanto, de acordo com Mesquita Filho e Torrent (1993), essas doses podem ser menores e os teores de P disponível maiores se for adicionado matéria orgânica em quantidade superior à empregada no presente estudo, em função de uma menor adsorção de $\mathrm{P}$.

\section{AGRADECIMENTOS}

Os autores agradecem aos agentes em Agropecuária, Francisco de Castro Azevedo, José Barbosa de Souza, Francisco Soares de Brito, Francisco Silva do Nascimento e Expedito de Souza Lima que viabilizaram a execução dos trabalhos de campo.

\section{LITERATURA CITADA}

ANDRADE, M.J.B.; KIKUTI, H.; ANDRADE, L.A.B.; REZENDE, P.M. Respostas do feijoeiro (Phaseolus vulgaris L) à adubação foliar fosfatada em solo com baixo teor de fósforo. Ciências $e$ Agrotecnologia, Lavras, v.22, n.2 p.188-193, 1998. COUTINHO, E.L.M.; NATALE, W.; SOUZA, E.C.A. Adubos e corretivos: aspectos particulares na olericultura. In: FERREIRA, M.E, CASTELLANE, P.D. CRUZ, M.C.P., coord. Nutrição e adubação de hortaliças. Jaboticabal-SP: Faculdade de Ciências Agrárias e Veterinárias. 1993, p.85-140.

DAY, P.R. Particle fractionation and particle size analysis. In: BLACK, C.A., ed. Methods of soil analysis. American Society of Agronomy, Madison, p.545-567, 1965.

EMPRESA BRASILEIRA DE PESQUISA AGROPECUÁRIA - EMBRAPA. Centro Nacional de Pesquisa de Solos. Sistema Brasileiro de Classificação de Solos. Brasília: Produções de Informações, 1999. 412 p.

FAGERIA, N.K. Calibração de análise de fósforo para arroz em casa de vegetação. Pesquisa Agropecuária Brasileira, Brasília, v.25, n.4, p.579586, 1990.

FILGUEIRA, F.A.R. Novo Manual de Olericultura: Agrotecnologia moderna na produção e comercialização de hortaliças, Viçosa, 2000, 402 p.
FONTES, P.C.R.; ROCHA, F.A.T.; MARTINEZ, H.E.P. Produção de máxima eficiência econômica da batata em função da adubação fosfatada. Horticultura Brasileira, Brasília, v.15, n.2, p.104107, 1997.

LOBATO, E. Adubação fosfatada em solos da Região Centro-Oeste. In: OLIVEIRA, A.J. LIURENÇO,S.; GOEDERT, W.J. Adubação fosfatada no Brasil. Brasília: EMBRAPA-DID, 1982. 209 p. (EMBRAPA - DID. Documento 21) LYMAN, J.M. Adaptation studies on lima beans accessions in Colombia. Journal of the American Society for Horticultural Science, v.108, p.369376, 1983.

MESQUITA FILHO, M.V; TORRENT, J. Phosphate sorption as related to mineralogy o a hidrosequence of soils from the Cerrado region (Brazil). Geoderma, v.58, p.107-123, 1993.

MOURA, W.M.; LIMA, P.C.; CASALI, V.W.D.; PEREIRA, P.R.G. Eficiência nutricional para fósforo em linhagens de pimentão. Horticultura Brasileira, Brasília, v. 19, n. 3, p. 306-312, 2001.

NATALE, W.; COUTINHO, E.L.M.; BOARETTO, A.; PEREIRA, F.M. Dose mais econômica de adubo nitrogenado para a goiabeira em formação. Horticultura Brasileira, Brasília, v.14, n.2, p.196-199, 1996.

NOVAIS, R.F.; SMYTH, T.J. Fósforo em solo e planta em condições tropicais. Viçosa: UFV, DPS, 1999. 399 p.

PASTORINI, L.H.; BACARIN, M.A.; LOPES, N.F.; LIMA, M.G.S. Crescimento inicial de feijoeiro submetido a diferentes doses de fósforo em solução nutritiva. Revista Ceres, Viçosa, v.47, n.270, p.219-228, 2000.

PRIMAVESI, A. Manejo ecológico do solo: a agricultura em regiões tropicais. 8: edição, São Paulo, ed. Nobel, 1985, 541 p.

RAIJ, B.V. Avaliação da fertilidade do solo. 2. ed. Piracicaba: Instituto da Potassa \& Fosfato, 1983. $142 \mathrm{p}$

RAIJ, B.V. Fertilidade do solo e adubação. Piracicaba: Ceres/Potafos, 1991. 343 p.

SAEG - Sistema para análise estatística, versão 8.0. Viçosa-MG: Fundação Artur Bernardes, 2000. SENO, S. SALIBA, G.G.; PAULA, F.J.; KOGA, P.S. Efeito de fósforo e húmus de minhoca, na cultura do alho (Allium sativum L.) cv. Roxo Pérola de Caçador. Horticultura Brasileira. v.12, n.1, p.76-78, 1994.

SILVA, E.B.; RESENDE, J.C.F.; CINTRA W.B.R. Resposta do feijoeiro a doses de fósforo em solo arenoso. Ciência Rural, Santa Maria, v.31, n.6, p.973-977, 2001a.

SILVA, E.C.; MIRANDA, J.R.P.; ALVARENGA, M.A.R. Concentração de nutrientes e produção do tomateiro podado e adensado em função do uso de fósforo, de gesso e de fontes de nitrogênio. Horticultura Brasileira, Brasília, v.19, n.1, p.6469, 2001b.

VIEIRA, C. Cultura do feijão. Viçosa. Universidade Federal de Viçosa, 1978, $146 \mathrm{p}$

VIEIRA, M.C. Avaliação do crescimento e da produção de cones e efeitos de resíduo orgânico e de fósforo em mandioquinha salsa no estado do Mato Grosso do Sul. Viçosa: UFV, 1995. 146 p. (Tese doutorado).

VIEIRA, M.C.; CASALI, V.W.D.; CARDOSO, A.A.; MOSQUIM, P.R. Crescimento e produção de mandioquinha-salsa em função da adubação fosfatada e da utilização de cama-de-aviário. Horticultura Brasileira, Brasília, v.16, n.1, p.6873, 1998.

VIEIRA, R.F. A cultura do feijão-fava. Informe Agropecuário, Belo Horizonte, v.16, n.174, p.3037, 1992. 